\title{
Opposing a granted patent in the USA: post grant and inter partes review
}

\author{
Paul A Ragusa*,1 \& Zichao Zhang ${ }^{1}$ \\ ${ }^{1}$ Baker Botts LLP, Intellectual Property New York, New York, NY 10112, USA \\ *Author for correspondence: Paul.Ragusa@bakerbotts.com
}

\section{' $a$ PGR should be used if the party wishes to challenge a patent beyond prior art grounds, or based on prior art that is not in the form of a patent or printed publication"}

First draft submitted: 7 March 2019; Accepted for publication: 29 March 2019; Published online: 10 June 2019

Keywords: inter partes review $\bullet$ patent invalidity $\bullet$ patent litigation $\bullet$ patent oppositions $\bullet$ post grant review

Although contentious, inter partes administrative proceedings to oppose a granted patent have been available for a long time in Europe and other jurisdictions, similar proceedings are relatively new in the USA. Historically, a party seeking to invalidate an issued USA patent at the United States Patent and Trademark Office (PTO) was limited to filing a request for ex parte reexamination (EPR). However, other than preparing an initial request for an EPR and a reply to the patent owner (if the patent owner responds to the request), such proceedings were and continue to be ex parte, and thus do not permit further participation by the party seeking to invalidate the patent [1].

The USA broadened the options to challenge an issued patent in 2000 by enacting a procedure called inter partes re-examination, which permitted further participation by the challenging party [2,3]. Inter partes re-examination proceedings were replaced by inter partes review (IPR) proceedings in 2012, by sweeping changes to USA patent law under the America Invents Act, and have grown in popularity since its inception. As of January 2019, a total of 9031 IPRs have been filed [4]. The grounds for challenging validity are limited for both IPRs and EPRs to anticipation and obviousness based on patents and printed publications [5]. However, in contrast to EPRs, IPRs permit a party to not only file a petition with the PTO, but also to fully participate in invalidity proceedings, including through discovery and an administrative trial.

The America Invents Act also created a third alternative to challenging issued patents, post grant review (PGR). While IPRs have been widely used, PGRs are just starting to gain momentum, in part because the procedure is available only for patents with an effective filing date on or after 16 March 2013 [6]. Unlike EPRs and IPRs, a PGR must be filed within 9 months after the issuance of a patent, so a decision to file a PGR needs to be made promptly after a patent issues [7]. This article compares the differences between PGR and IPR to facilitate considerations for choosing between them.

\section{Grounds of invalidity}

One of the key distinctions between PGR and IPR is the available grounds for invalidity challenges. In a PGR, a petitioner can pursue diverse grounds of invalidity that include patent-ineligible subject matter, anticipation, obviousness, lack of sufficient written description, lack of enablement and/or lack of clarity [8]. In contrast, IPR allows challenges based on anticipation and obviousness only, and the basis is limited to patents and printed publications [9]. Therefore, a PGR should be used if the party wishes to challenge a patent beyond prior art grounds, or based on prior art that is not in the form of a patent or printed publication. Indeed, asserting invalidity based on lack of sufficient written description or enablement, can be an important approach for challenging certain pharmaceutical or biological patents in a PGR [10]. However, if prior art patents or printed publications provide the most promising invalidity grounds, then the choice between PGR and IPR may be determined by other distinctions. 


\section{Timing of filing a petition}

Another important distinction between PGR and IPR is the timing of filing a petition. A PGR must be filed within 9 months after issuance or reissue of a PGR-eligible patent; whereas, an IPR is available for such patents 9 months after issuance or reissue, or after the termination of a PGR, whichever is later [11]. An IPR can also be filed within 9 months after the issuance or reissue of a patent having an effective filing date prior to $16 \mathrm{March} 2013$ [12]. Therefore, the timing of filing a petition in these two proceedings is mutually exclusive. For a petitioner who is not under significant time pressure and chooses to rely on patents or printed publications for invalidity challenges, an IPR may be a better option. However, seeking to institute a PGR may be a petitioner's choice if time is of the essence, for example, when a patent is asserted in an infringement suit and the petitioner cannot afford to wait 9 months, or when a petitioner needs to invalidate a patent to clear manufacturing of a product. The drawbacks of pursuing a PGR include less time to prepare, early commitment of potentially significant costs and broader estoppel, which will be discussed below. Time and cost burdens can be reduced with respect to a newly issued patent having similar family members in the USA or elsewhere that were previously investigated or litigated.

\section{Scope of discovery}

Both IPRs and PGRs offer limited discovery as compared with litigation in the USA. Routine discovery is generally limited to: exhibits cited in a paper or in a testimony; relevant information that is inconsistent with a position advanced by the party and cross-examination of the other party's witnesses who have submitted an affidavit or a declaration [13]. A party requesting additional discovery must show that it is necessary in the interest of justice (for an IPR), or that it is for good cause (for a PGR). The PGR 'good cause' standard carries a lower burden as compared with the 'in the interest of justice' standard [14,15]. Furthermore, additional discovery in a PGR requires relevant evidence to be "directly related to ... factual assertions advanced by either party." [16]

The broader scope of discovery available in a PGR can be a double-edged sword for a petitioner. On one hand, more evidence may be available to support an invalidity challenge, such as results in an inventor's laboratory notes on the issue of enablement. On the other hand, a petitioner may itself need to produce broader discovery and/or incur additional costs from offensive and defensive discovery. Therefore, careful consideration should be made concerning the availability of additional grounds or other perceived benefits of filing a PRG rather than an IPR.

\section{Estoppel}

Estoppel is another important aspect to consider when choosing between a PGR and an IPR. Estoppel can arise when a party brings a petition for IPR or PGR that is instituted by the PTO, and then latter attempts to challenge the validity of the same patent claim in a later administrative proceeding at the PTO or in litigation [17]. According to the relevant statutes, the scope of estoppel can extend to both the 'petitioner..., or the real party in interest or privy of the petitioner' and apply to preclude that party from challenging the validity of the same patent claim on any ground that the petitioner raised or reasonably could have raised during the proceeding [18]. Because it permits additional grounds to be asserted, a PGR can lead to a broader estoppel effect on the petitioner, extending beyond grounds based on patents or printed publications.

The law regarding the scope of estoppel is still evolving [19,20]. For example, in Koninklijke Philips v. Wangs Alliance, the court held that estoppel attached to grounds that were actually instituted [21]. In contrast, the court in Oil-Dri Corp. of Am. v. Nestle Purina Petcare took a broader view of estoppel, finding that estoppel would apply to grounds beyond what was asserted in the IPR petition [22]. In BTG Int'l v. Amneal Pharm, a case involving a patent covering a prostate cancer drug, the Federal Circuit may soon decide whether a successful argument in an IPR is subject to estoppel in district court litigation [23]. The decision may impact strategy regarding whether to challenge patent validity in the PTO or in a district court.

\section{Other areas of consideration}

Other distinctions between PGR and IPR include the standard applied by the PTO to determine whether to initiate a proceeding, costs and predictability. A petitioner of a PGR must meet a higher standard compared with that of an IPR: an PGR petition must show that it is more likely than not that at least one of the claims challenged in the petition is unpatentable [24]; whereas, an IPR petition must show that there a reasonable likelihood that a petitioner would prevail [25]. This difference may not have a significant impact to the chance of final success of an invalidity challenge, as the burden of proof of invalidity is preponderance of the evidence in both an IPR and a PGR [26,27]. 
Regarding costs, a PGR is likely to cost more than an IPR due to the broader availability of grounds and wider scope of discovery. Additionally, the outcome of an IPR can be more predictable compared with PGR, since the likelihood of success of an IPR can be assessed largely based on the strength of the available patents and other prior art references. In comparison, the results of a PGR can vary depending on the asserted grounds for invalidity.

\section{Conclusion}

Filing a petition for a PGR can be necessary for qualifying patents where time is of essence, if grounds that do not rest on prior art are needed, or if critical prior art is not in the form of a patent or printed publication. An IPR may be preferred where grounds resting on prior art patents and printed publications are the most promising invalidity positions, and for PGR qualifying patents, where the petitioner can afford to wait before filing a petition. Given the greater importance of the written description and enablement requirements in pharmaceutical patents compared with patents in other fields, pharmaceutical companies may drive a continued increase in PGR filings.

\section{Financial \& competing interests disclosure}

Paul Ragusa is a partner, and Zichao Zhang is an associate, in the New York, NY office of Baker Botts LLP, where they both practice intellectual property law, including relating to the issues addressed in this article. The authors have no other relevant affiliations or financial involvement with any organization or entity with a financial interest in or financial conflict with the subject matter or materials discussed in the manuscript apart from those disclosed.

No writing assistance was utilized in the production of this manuscript.

\section{References}

1. 37 C.F.R. $\S \S 1.525-1.565$.

2. 35 U.S.C. $\S \S 311-318$.

3. 37 C.F.R. $\S \S 1.902-1.997$.

4. The United States Patent and Trademark Office. www.uspto.gov/sites/default/files/documents/trial_statistics_jan2019.pdf

5. 35 U.S.C. $\S \S 301-302,311$ (b).

6. 35 U.S.C. $\S 321$ (note)(1)(A).

7. 37 C.F.R $\S 42.202$.

8. 35 U.S.C. $\S \S 101,102,103,112$ and $321($ b).

9. 35 U.S.C. $\S \S 102,103$ and $311(\mathrm{~b})$.

10. Grünenthal GmbH v. Antecip Bioventures II LLC, Patent Trial and Appeal Board. No. PGR2017-00008 (2017).

11. 37 C.F.R $\S 42.102$ and 202.

12. Amazon.com, Inc., v. Digital Media Technologies, Inc, Patent Trial and Appeal Board. IPR2017-00285, Paper No. 12 (2017).

13. 37 C.F.R $\S 42.51(b)(1)$.

14. 77 Fed. Reg. 48680, 48693 (Aug. 14, 2012).

15. Bloomberg, Inc., v. Markets-Alert Pty Led., Patent Trial and Appeal Board. CBM2013-00005, paper 32 (2013).

16. 37 C.F.R $\S 42.51(\mathrm{~b})(1)$.

17. 35 U.S.C. $\S \S 315(\mathrm{e})$ and $325(\mathrm{e})$.

18. 35 U.S.C. $\S \S 315(\mathrm{e})$ and $325(\mathrm{e})$.

19. Shaw Indus. Grp., Inc., v. Automated Creel Sys., Inc., Federal Circuit Court. 817 F.3d 1293 (2016).

20. Credit Acceptance Corp. v. Westlake Servs., Federal Circuit Court. 859 F.3d 1044, 1053 (2017).

21. Koninklijke Philips N.V. v. Wangs Alliance Corp., District Court for the District of Massachusetts. No. CV 14-12298-DJC, 2018 WL 283893 (2018).

22. Oil-Dri Corp. of Am. v. Nestle Purina Petcare Co., District Court for the Northern District of Illinois. No. 15-CV-1067, ECF No. 224 (2018).

23. BTG Int'l Ltd. v. Amneal Pharm., Federal Circuit Court. No. 2019-1147 (2018).

24. 35 U.S.C. $\S 324(\mathrm{a})$.

25. 35 U.S.C. $\S 314(\mathrm{a})$.

26. 37 C.F.R $\S 42.1(d)$.

27. In re Baxter Int'l, Inc., Federal Circuit Court. 678 F.3d 1357, 1365 (2012). 